Смоляков В. А.

МИГРАЦИОННАЯ СИТУАЦИЯ И ПОЛИТИКА ИНТЕГРАЦИИ МИГРАНТОВ В СТРАНАХ ОРГАНИЗАЦИИ

ЭКОНОМИЧЕСКОГО СОТРУДНИЧЕСТВА И РАЗВИТИЯ

Смоляков В. А.

V. A. Smolyakov

МИГРАЦИОННАЯ СИТУАЦИЯ И ПОЛИТИКА ИНТЕГРАЦИИ МИГРАНТОВ В СТРАНАХ ОРГАНИЗАЦИИ ЭКОНОМИЧЕСКОГО СОТРУДНИЧЕСТВА И РАЗВИТИЯ

\title{
MIGRATION SITUATION AND POLICY OF INTEGRATION OF MIGRANTS IN THE COUNTRIES OF THE ORGANIZATION FOR ECONOMIC COOPERATION AND DEVELOPMENT
}

Смоляков Владимир Александрович - доктор политических наук, профессор кафедры социальногуманитарных наук Хабаровского государственного университета экономики и права (Россия, Хабаровск); 680030, г. Хабаровск, ул. Ленина, 41. E-mail: Smolyakov46@mail.ru.

Mr. Vladimir A. Smolyakov - is the doctor of political sciences, professor of department of the social and humanities of the Khabarovsk State University of economy and the law (Russia, Khabarovsk); 680030, Khabarovsk, 41 Lenin str. E-mail: Smolyakov46@mail.ru.

Аннотация. Концепция интеграции используется с различными значениями. В данной статье определяются признаки «успешной» интеграции на «выходе». Автор рассматривает особенности политики интеграции в странах Организации экономического сотрудничества и развития (ОЭСР), расходы на интеграцию и проблему адаптации мигрантов.

Summary. The concept of integration is used with widely differing meanings. In this article are determined signs of «successful» integration at the «output». Autor is discussing the specifics of the integration policy in the countries of OECD, the costs of integration and the problem of adaptation of migrants.

Ключевые слова: миграция, интеграция, ОЭСР, мультикультурализм, сегментированная ассимиляция.

Key words: migration, integration, OECD, multiculturalism, segmented assimilation.

УДК 331.556 .44

Одним из самых ярких событий в эпоху глобализации являются массовые переезды людей через национальные границы. Согласно данным, опубликованным Департаментом по экономическим и социальным вопросам ООН, в настоящее время в принимающих странах проживает около 258 млн. человек, что на 49 \% больше, чем в 2000 году [2, 1]. Обязательным признаком международной миграции является пересечение государственных границ. В международно-правовых документах $\mathrm{OOH} \mathrm{и} \mathrm{ЕС} \mathrm{мигрантом} \mathrm{признаётся} \mathrm{любое} \mathrm{лицо,} \mathrm{которое} \mathrm{покидает} \mathrm{своё} \mathrm{прежнее} \mathrm{место} \mathrm{жи-}$ тельства и пересекает границы другого государства с целью поселиться в нём на более-менее длительное время (минимум на 12 месяцев) [6, 1]. В Международном докладе о миграции за 2017 год (основные моменты), который публикуется раз в два года, говорится, что 3,4 \% жителей мира являются международными мигрантами. В то же время количество мигрантов как доли населения, проживающего в странах с высоким доходом, увеличилось с 9,6 \% в 2000 году до 14 \% - в 2017-м. В 2017 году страны с высоким уровнем доходов принимали почти 165 млн. человек, или 64 \% от общего числа международных мигрантов во всём мире [2, 1]. Современная миграционная волна имеет ряд особенностей: во-первых, это беспрецедентное число незарегистрированных, или «нелегальных» мигрантов; во-вторых, доминирование больших групп из мусульманских стран, религиозная идентичность которых принципиально отлична от ценностей принимающего общества; в-третьих, это тенденция иммигрантов образовывать долговременные диаспоры и поддерживать тесные связи со странами происхождения; в-четвёртых, в XXI в. мигранты в большей степени, чем раньше, привозят с собой всё более разнообразные экономические, социальные и культурные традиции и всё чаще не хотят принимать ценности и нормы принимающих стран. 


\section{Учёные записки}

Комсомольского-на-Амуре государственного технического университета

Серьёзным фактором, приведшим к перегрузке и даже кризису миграционных систем стран назначения миграционных потоков, стал мощный подъём волны беженцев в 2015-2016 гг., в значительной мере спровоцированный гражданской войной в Сирии. К странам происхождения миграционных потоков относятся Алжир, Марокко, Тунис, Эфиопия, Нигерия, Турция, Пакистан, Афганистан, Шри-Ланка, Китай и др.

Об актуальности рассматриваемой в данной статье темы свидетельствует сложившаяся в мире напряжённая миграционная ситуация, которая представляет собой подобие двусторонней медали - неразрывные процессы миграции и интеграции в принимающих государствах.

Целью данной статьи является ознакомление читателя с опытом решения миграционной проблемы и политики интеграции в странах ОЭСР (англ. Organization for Economic Cooperation and Development, OECD). Автор исходит из того, что этот опыт представляет интерес и для России, которая занимает четвёртое место в мире по количеству мигрантов, поскольку обладает миграционной привлекательностью для жителей стран СНГ $[2,2]$. В настоящей статье автор знакомит с распространёнными трактовками понятия «интеграция» и выдвигает широкое определение данного термина.

Наиболее привлекательным местом для мигрантов и беженцев были и остаются 35 стран ОЭСР, включая Европейский Союз, который участвует в организации на правах отдельного члена. Объективность требует признать, что эта группа стран представляет собой демократии с высоким доходом и леволиберальной политикой в вопросах прав человека, социального обеспечения. По отчётам за 2016 год социальные расходы всех государств ОЭСР в среднем достигли более $21 \%$ от ВВП, в том числе во Франции - 32 \%, в Германии - 26 \%, в США - 19 \% и т. д. [13, 1]. В этих странах действуют в разной степени профинансированные программы приёма беженцев.

Привлекательность стран ОЭСР постоянно возрастает. Только за 2015 год в них направилось почти 3/4 всех мигрантов. В течение 2016 года в ОЭСР въехали 5 млн. мигрантов, что явилось самым высоким показателем за последние десятилетия [3]. В настоящее время доля иностранцев и граждан, родившихся за границей, составляет в ЕС около 14 \%, причём в эту категорию входят и европейцы, воспользовавшиеся отсутствием внутренних границ и приехавшие из-за пределов Европы. Примерно такая же доля мигрантов уже более 100 лет сохраняется в Соединённых Штатах Америки [15, 3].

Возникновение чрезвычайного этнического многообразия в традиционно моноэтнических государствах так же, как и политизация миграционной тематики в публичных дискуссиях, повысили интерес к проблеме «включения» мигрантов в принимающие общества. Мигранты - это люди и группы, которые оказались в новой для них социальной среде с другой культурой, к которой им необходимо приспособиться. В связи с этим не случайно возникает конфликтная ситуация между приезжими носителями иноземных культур и титульным населением, которое выступает за сохранение аутентичности своих обществ.

В связи с тем, что в европейском политкорректном дискурсе сложилась негативная коннотация термина «ассимиляция» (ассимиляция ассоциировалась с принудительным навязыванием господствующей культуры национальным меньшинствам), в теорию и практику иммиграционной политики были включены новые понятия - «интеграция» и «адаптация». Однако значение термина «интеграция» не было со всей необходимой ясностью определено, что открыло простор для его различных трактовок. Получили распространение как различающиеся в нюансах, так и противоположные по смыслу трактовки нового понятия.

Основываясь на обзоре попыток определения термина и опыте полевой работы по расселению беженцев в Великобритании, А. Агер и Э. Странг в статье «Понимание интеграции: концептуальные основания» устанавливают главные элементы, необходимые, по их мнению, для «успешной» интеграции. В статье предлагаются следующие главные условия интеграции: 1) получение доступа к таким сферам жизнедеятельности, как работа, жилище, образование и здравоохранение; 2) обязательства и практика в отношении гражданства и прав; 3) установление и поддержание социальной связи внутри групп и между группами внутри сообщества; 4) структурные барьеры для такой связи, связанные с языком, культурой и местной средой $[1,168]$. 
Смоляков В. А.

МИГРАЦИОННАЯ СИТУАЦИЯ И ПОЛИТИКА ИНТЕГРАЦИИ МИГРАНТОВ В СТРАНАХ ОРГАНИЗАЦИИ

ЭКОНОМИЧЕСКОГО СОТРУДНИЧЕСТВА И РАЗВИТИЯ

Итак, что означает понятие «интеграция»? Современное осмысление данного понятия включает в себя политический, экономический, административно-правовой и культурный аспекты. Интеграция в широком смысле слова - это процесс создания, упрочения и развития связей человека с социумом, который обеспечивает его включённость в основные сферы жизнедеятельности: труд, общение, быт, досуг, политику. В самом широком смысле интеграция включает не только адаптацию мигрантов, но и изменения в установках аборигенного населения. Обобщая многие дефиниции, в данной статье предлагается следующее определение этого понятия: интеграция в её практическом измерении - это комплекс мер по приёму, психологической адаптации, обучению, трудоустройству и включению индивида в жизнь гражданского общества, основанного на терпимости.

Представляется, что интеграция - это не столько результат, сколько сложный, внутренне противоречивый и многосторонний процесс. Как и всякий процесс, интеграция проходит через определённые этапы. Так как деятельность по интеграции носит комплексный характер, её следует рассматривать в качестве единой системы. Эту системную деятельность лучше анализировать с применением категорий «вход» и «выход». На входе политика интеграции включает три последовательных этапа: шаг первый - приём мигранта в страну, решение проблем по его временному размещению в пунктах приёма и содержанию, обучению языку принимающей страны в необходимом объёме; шаг второй - предоставление дополнительного образования и обучение рабочим профессиям; третий, самый трудный этап - выход мигранта на рынок труда, предоставление гражданства и подключение его к системе социальной защиты.

Исследователи разделили понятие интеграции на две широкие категории: 1) структурная интеграция, под которой понимают доступ мигрантов к занятости, жилью, образованию и политическим правам; 2) социокультурная интеграция, например, стратегия поведения мигрантов, их готовность к принятию новых для себя культурных норм и образцов поведения, соответствие идентичности окружающему обществу.

Эффективным инструментом интеграции является натурализация - юридический процесс приобретения гражданства на основе добровольного желания соискателя. Это расширяет доступ иммигрантов к занятости, системе образования и социального обеспечения. Не имея гражданства принимающей страны, иммигранты не могут полностью раскрыть свои потенциальные возможности как личности и ограничены во взаимодействиях с гражданским обществом. Кроме того, наличие гражданства даёт любому большее чувство принадлежности и стимулирует как политическое, так и профессиональное участие наравне с другими гражданами.

Имеются различные системы классификации международных мигрантов. Одна из систем делит миграционные потоки на четыре весьма широкие категории:

1. Трудовые мигранты, официально получившие право на жительство и работу. В соответствии с оценками Международной организации труда (МОТ) за 2015 год в мире насчитывалось 150 млн. трудовых мигрантов, что составляет более $65 \%$ от общей численности трансграничных мигрантов [5, xii]. В составе международных мигрантов доля лиц трудоспособного возраста от 20 до 64 лет составляет, по данным за 2017 год, около трёх четвертей (74 \%). Это значительно больше 57 \% трудоспособных в мировом населении.

Решение задачи трудоустройства зависит от участия в процессе трёх сторон: миграционных органов, предпринимателей и самого мигранта. Статистика показывает, что, например, в Европе из основных категорий мигрантов трудоустраиваются раньше всех трудовые мигранты, из которых находят себе работу в первый же год $75 \%$. На втором месте по трудовой активности стоят семейные мигранты - $40 \%$; на последнем месте беженцы - из них в течение первого года начинают трудиться менее $20 \%$. Однако через 15-19 лет между всеми категориями происходит выравнивание на уровне 70-75\%. Согласно расчётам эффективность отдачи от каждого трудящегося мигранта со временем только возрастает. С другой стороны, с каждым годом государственные расходы на каждого мигранта снижаются. Например, в Швеции за семилетний период они сокращаются на одного человека с 14 тыс. евро до 4 тыс. евро в год [4].

Экономический успех интеграции измеряется пополнением рынка рабочей силы. За период c 2000 по 2011 годы иммигранты давали 47 \% прироста рабочей силы в государствах ОЭСР 


\section{Учёные записки}

Комсомольского-на-Амуре государственного технического университета

и 70 \% - в Европе. Авторы ряда эмпирических исследований пробовали оценить экономические последствия миграции. В одном из исследований было проанализировано влияние миграции на экономический рост в 22 странах ОЭСР за период с 1986 по 2004 годы. В нём делается вывод о положительном, но незначительном воздействии нового человеческого капитала на рост ВВП принимающих стран. По мнению авторов, чистый эффект был невелик. Увеличение на 50 \% чистой миграции лиц, родившихся за границей, давало менее $0,1 \%$ изменения производительности $[10,255]$. Тем не менее недавно проведённые исследования указывают на более весомый вклад мигрантов в экономику стран ОЭСР. Так, например, в Швейцарии и Люксембурге иммигранты обеспечивают чистую экономическую выгоду, давая около 2 \% прироста ВВП. Таким образом, мигранты не являются бременем для западных стран и оказывают в целом положительное влияние на их экономику, причём занятость является наиболее заметным источником дополнительных налоговых поступлений [4].

2. Семейный поток, который по-прежнему остаётся основным для легальной миграции. В 2015 году количество семейных мигрантов составляло около 400 тыс. человек, то есть почти $40 \%$ всех постоянных въездов в страны ОЭСР. Кроме того, в Европе осуществляется примерно 30 \% внутриевропейских переездов, связанных с семейными причинами [9]. Семейные мигранты, как правило, сталкиваются с более сложными проблемами интеграции и обычно имеют менее благоприятные результаты, чем экономические мигранты, которые выбираются в соответствии с их перспективами интеграции на рынке труда. Они также часто не имеют специальности. Многие женщины прибывают из тех стран, где по традиции работает только один член семьи - мужчина. Чтобы преодолеть эти и другие трудности, связанные с ограниченным владением языком страны пребывания и другими недостатками в области квалификации и трудовых навыков, а также с нехваткой знаний о рынке труда принимающей страны или проблемами, связанными с уходом за детьми, многие семейные мигранты особенно нуждаются во вспомогательных услугах, таких как консультирование или социальное обеспечение для инвалидов.

Относительно либеральная политика стран ОЭСР в вопросах воссоединения или создания семей объясняется не только гуманитарными соображениями, но и пониманием того, что без решения этого экзистенциального вопроса успешная адаптация оставшегося на постоянное пребывание в гостевой стране мигранта окажется неосуществимой. Поскольку международные мигранты составляют большую долю лиц трудоспособного возраста по сравнению с общей численностью населения, чистый приток мигрантов снижает коэффициент зависимости от продолжительности жизни, то есть число детей и пожилых людей по сравнению с показателями трудоспособного возраста $[14,2]$. Старение Европы относится к числу наиболее серьёзных проблем ЕС. Долгосрочный социально-экономический потенциал континента ограничен надвигающимся демографическим кризисом. Коэффициент рождаемости в ЕС немногим выше 1,5 детей на одну женщину. Это представляет серьёзную проблему для системы социального обеспечения, включая пенсии, а также здоровье и долгосрочный уход. Согласно статистике Евростата доля населения в возрасте 65 лет и старше ещё больше возрастёт - с 18,5 \% в 2014 году до 28,4 \% - в 2060-м. Как следствие, соотношение людей трудоспособного возраста (15-64 лет) и тех, кто старше 65 лет, снизится с 4 к 1 в 2013 году и с 2 к 1 - к 2060-му. В одном из отчётов говорится: «Это очень острая проблема, поскольку ряд лет Европа предпринимает своего рода коллективное демографическое самоубийство. Изменить демографические тенденции, способствующие увеличению рождаемости, недостаточно. Это также должно быть сделано через иммиграцию» $[6,1]$. В целях смягчения демографической проблемы эксперты призывают к поддержке семей, чтобы увеличить коэффициент рождаемости, а также разработать контролируемую миграцию и стабильную интеграционную политику. В целом, миграционный прирост обеспечивает не менее половины, а в некоторые годы и свыше $80 \%$ от общего прироста численности населения стран Европы $[6,2]$.

3. Значительной движущей силой наплыва миграции в 2015-2016 годах стали беженцы, которых в Европе называют «гуманитарными мигрантами». Беженец - это индивид, который покидает своё государство в надежде на получение статуса политического беженца и соответствующей государственной защиты в политически стабильной демократии либо вследствие кризиса и граж- 
Смоляков В. А.

МИГРАЦИОННАЯ СИТУАЦИЯ И ПОЛИТИКА ИНТЕГРАЦИИ МИГРАНТОВ В СТРАНАХ ОРГАНИЗАЦИИ

ЭКОНОМИЧЕСКОГО СОТРУДНИЧЕСТВА И РАЗВИТИЯ

данской войны у себя на родине, либо из-за преследований по религиозным, этническим, политическим и иным причинам. В международном докладе о миграции за 2017 год, публикуемом раз в 2 года, говорится, что в число международных мигрантов вошли 26 млн. беженцев или лиц, ищущих убежища, то есть около 10 \% от общего числа мигрантов [14].

Политика интеграции беженцев - дело дорогостоящее, требующее высоких расходов, которые ложатся на плечи налогоплательщика в странах приёма. И эти расходы из года в год растут. Страны Евросоюза за первый год расходуют в среднем по 8-12 тыс. евро на каждого прибывающего мигранта. Германия тратила по 0,5 \% ВВП в год из государственных расходов - в 2016 и 2017 годах - для удовлетворения первоначальных потребностей вновь прибывших иммигрантов и их интеграции на рынке труда. Другие страны ЕС также внесли свой вклад в устройство мигрантов: Австрия израсходовала 0,3 \% ВВП, Швеция - 0,9 \% от ВВП в 2016 году. Турецкое правительство оказывало помощь сирийцам с 2011 года, что эквивалентно 0,8 \% ВВП в 2014-м. [16, 4].

4. Образовательная мигращия поощряется правительствами западных стран, и поэтому отношение чиновников к студентам лучше, чем к беженцам. В государствах ОЭСР численность лиц, которые получили первичное разрешение на пребывание (аналог российского разрешения на временное пребывание - РВП) для прохождения учёбы, увеличилось в 2015 году на 11 \% и составило 1,5 млн. разрешений $[8,3]$.

Кто отвечает за интеграцию? И в странах ОЭСР, и в Европе нет единой системы подхода к беженцам. Особенностью государственной миграционной политики стран - членов Евросоюза является то, что она реализуется на трёх уровнях. Первый уровень - это межгосударственные соглашения стран ЕС, или обязывающие решения на уровне институтов ЕС. Второй уровень - внутренняя миграционная политика отдельных стран ЕС. Самый нижний уровень миграционной политики - это субнациональный уровень провинций и муниципалитетов.

В Соединённых Штатах Америки на федеральном уровне нет органа, ответственного за интеграцию. Поэтому интеграция иммигрантов в первую очередь является задачей местных органов власти и гражданского общества, а федеральная программа переселения беженцев помогает вновь прибывшим на этапе приёма в страну. Другая система сложилась во многих странах ОЭСР, в которых функционирует разделение ответственности по приёму и интеграции мигрантов между двумя уровнями - центральными правительствами и местными органами управления (провинциями и муниципалитетами) (см. табл. 1).

Таблица 1

Разделение задач и функций по интеграции мигрантов между двумя уровнями

\begin{tabular}{||l|l|}
\hline \multicolumn{1}{|c|}{ Центральное правительство } & \multicolumn{1}{|c|}{ Местные органы управления } \\
\hline Постановка на учёт & Начальное и среднее образование \\
\hline $\begin{array}{l}\text { Рассмотрение заявлений о предоставлении } \\
\text { убежища и защиты }\end{array}$ & Социальная защита, минимальное пособие \\
\hline $\begin{array}{l}\text { Пункты приёма (лагеря беженцев), } \\
\text { временное жильё }\end{array}$ & Постоянное жилище после лагеря беженцев \\
\hline Первая экстренная помощь & Помощь мигранту на рынке труда \\
\hline $\begin{array}{l}\text { Обучение языку страны приёма в необходимом } \\
\text { объёме }\end{array}$ & Продвинутый курс обучения языку \\
\hline $\begin{array}{l}\text { Начальные курсы «цивикс»- обучение осно- } \\
\text { вам обществоведения }\end{array}$ & $\begin{array}{l}\text { Ресоциализация в структурах гражданского } \\
\text { общества }\end{array}$ \\
\hline Высылка отдельных категорий мигрантов & \\
\hline
\end{tabular}

Следует отметить, что данное разделение имеет место как в федеративных, так и в унитарных государствах. В странах ОЭСР величина расходов провинциальных и муниципальных правительств (sub-central governments) на устройство беженцев составляет 35-45\% от величины общегосударственных расходов. Но интеграция - это не только процесс, идущий сверху вниз, 


\section{Учёные записки}

Комсомольского-на-Амуре государственного технического университета

то есть полагающийся на государственную политику. Решение этой задачи зависит и от сообществ волонтёров, и инициатив некоммерческих гражданских организаций.

При неспособности или нежелании мигрантов адаптироваться к новым условиям работы и жизни, приспосабливаться и принимать во внимание образ жизни и культуру титульного населения у последнего могут усилиться ксенофобские и националистические настроения. Антимигрантский настрой выливается, как правило, в поддержку ультраправых, националистических партий и организаций, призывающих к защите национальной идентичности. Актуальность этой проблемы выявилась со всей остротой в связи с «миграционным кризисом» 2015-2016 годов. Миграционный поток привёл к особенно быстрой и глубокой трансформации многих обществ ЕС; нигде это явление не проявляется более отчётливо, чем на городских окраинах, где сосредоточены мусульманские общины. Доминирование в миграционном потоке беженцев из мусульманских стран привело к острому кросскультурному конфликту.

К сложностям процесса аккультурации относится типичная поведенческая стратегия религиозно настроенных мигрантов, которая характеризуется крайней интолерантностью к ценностям и нормам западной цивилизации. Этноцентризм в этом случае выражается в том, что культура принимающих обществ осуждается и отвергается. Хуже того, мигранты стараются транспортировать свои этнические стереотипы в новую среду, навязать принимающему обществу собственное средневековое мировоззрение и образ жизни. Особенно тревожной стала новая тенденция - распространение среди мигрантов радикального ислама. Растёт и криминализация этой части населения - тенденция стала устойчивой. Согласно одному исследованию новые миграционные волны заметно отличаются не только этно-религиозным составом, но и более низким уровнем образования и отсутствием квалификации. Это неизбежно приводит к росту межэтнической напряжённости, в том числе в связи с высокой степенью криминализации мигрантской среды. Однако, как оказалось, не менее серьёзной проблемой стало проникновение мигрантов в сельскую местность. Они там не работают и предпочитают заниматься криминальным бизнесом $[7,283]$.

Возникшие острые политические проблемы поставили на повестку дня вопросы о допустимости длительного сосуществования внутри одного общества разнородных культур и завезённых извне чужих цивилизационных признаков. Европейские правительства совершили много ошибок в решении этой проблемы. Модель мультикультурализма, которая до недавнего времени лежала в основе политики интеграции мигрантов, допускает, что мигранты, которые приобрели глубоко укоренившиеся и устойчивые социальные нормы и культурные стереотипы в местной общине у себя на родине, будут сохранять свою культуру и после переезда. Таким образом, группы меньшинства должны сохранять устойчивые традиции, собственную идентичность и глубоко укоренившиеся ценности много десятилетий или даже веков.

Альтернативой мультикультурализму является теория и практика ассимиляции, основанная на опыте США. Однако в связи с недостаточной реалистичностью теории и практики ассимиляции более прагматичной представляется компромиссная концепция «сегментированной ассимиляции», разработанная А. Портсом и М. Чжоу. Данная идея предполагает вначале лишь частичный переход мигрантов на культурные позиции принимающего общества и полную ассимиляцию лишь во втором или третьем поколении [11].

Миграционный кризис и неудачи политики культурной интеграции привели к росту ксенофобских настроений. Вот почему крайне важно иметь чёткое понимание фактов. Выходом из межэтнических противоречий следует считать более глубокую культурную интеграцию при непременном соблюдении демократических ценностей, инклюзивности и прав человека.

\section{ЛИТЕРАТУРА}

1. Ager, A. Understanding Integration: A Conceptual Framework / A. Ager, A. Strang // Journal of Refugee Studies. - 2009. - № 21(2). - P. 166-191.

2. International Migration Report // Department of Economic and Social Affairs. - 2017. - Highlights. United Nations. - New York, 2017.

3. International Migration Outlook. - Paris: OECD, 2017 // URL: www.oecd.org/els/migration/imo. 
Смоляков В. А.

МИГРАЦИОННАЯ СИТУАЦИЯ И ПОЛИТИКА ИНТЕГРАЦИИ МИГРАНТОВ В СТРАНАХ ОРГАНИЗАЦИИ

ЭКОНОМИЧЕСКОГО СОТРУДНИЧЕСТВА И РАЗВИТИЯ

4. Is Immigration good for the economy? // OECD, Migration Policy Debates. May, 2014.

5. Global estimates of migrant workers and migrant domestic workers: results and methodology // International Labour Office. - Geneva: ILO, 2015. - P. xi.

6. Karakas, C. Economic challenges and prospects of the refugee influx / C. Karakas // Briefing December - 2015. European Parliamentary Research Service.

7. Kéri, S. Religious Conversion to Christianity in Muslim Refugees in Europe / S. Kéri, C. Sleiman // Archive for the Psychology of Religion. - 2017. - Vol. 39. - P. 283.

8. Launch of the 2017 International Migration Outlook // Angel Gurría OECD Secretary-General, Paris // 2017, Thursday 29 - June 2 // URL: http://www.oecd.org/about/secretary-general/launch-of-the-2017-internationalmigration-outlook.htm.

9. Making Integration Work: Family Migrants, OECD. 2017. Publishing, Paris // URL: http://dx.doi.org/10.1787/9789264279520-en.

10. Massey, J. E. International Migration: Prospects and Policies in a Global Market / J. E. Massey, Taylor (eds.). Oxford University Press, 2007.

11. Portes, A. The new second generation: segmented assimilation and its variants / A. Portes, M. Zhou // American Academy of American Academy of Political and Social Science. - 1993. - № 530. - P. 74-96.

12. Portes A. Children of immigrants: segmented assimilation / A. Portes // Economic Sociology of Immigration. Ed. Alejandro Portes. - Russell Sage, 1995.

13. Social spending stays at historically high levels in many OECD countries /. Social Expenditure Update. October, 2016 // URL: http://www.oecd.org/els/soc/OECD2016-Social-Expenditure-Update.pdf.

14. STESA/SER.A/404. Department of Economic and Social Affairs // International Migration Report, 2017. Highlights: United Nations, 2017.

15. The U. S. Immigration Debate. Introduction. Backgrounder by Claire Felter, F. Danielle Renwick, D. Last updated. - March 13, 2018.

16. Who bears the cost of integrating refugees? // Migration policy Debates. OECD. - January, 2017. 